\title{
Galinhas semipesadas em postura criadas sobre diferentes tipos de cama
}

\author{
Semi-posed hens reared on different bed types
}

\author{
MOURA, Glenda Roberta Silva ${ }^{1 *}$; MENDONÇA, Michele de Oliveira ${ }^{1}$; SALGADO, \\ Hallef Rieger ${ }^{1}$; CASTRO, Jaqueline de Oliveira ${ }^{2}$; SOUZA, Rafael Teixeira de ${ }^{1}$
}

\author{
${ }^{1}$ Instituto Federal de Educação Ciência e Tecnologia do Sudeste de Minas, Departamento Acadêmico de \\ Zootecnia, Rio Pomba, Minas Gerais, Brasil. \\ ${ }^{2}$ Universidade Federal de Lavras, Departamento de Zootecnia, Lavras, Minas Gerais, Brasil. \\ *Endereço para correspondência: glendarmoura@gmail.com
}

RESUMO

No sistema de criação em piso as galinhas são criadas diretamente em contato com o chão que pode ser coberto por diferentes tipos de materiais. Objetivou-se avaliar o ambiente térmico, o comportamento, os índices zootécnicos e a qualidade de ovos de galinhas poedeiras criadas em dois tipos de piso, maravalha e grama sintética. Foram utilizadas 120 galinhas da linhagem Hisex Brown $^{\circledR}$, destas, metade foi criada sobre maravalha e a outra metade sobre grama sintética (Tapete Astro Turf $^{\circledR}$ ) distribuídas em um delineamento inteiramente casualizado em medidas repetidas no tempo, com dois tratamentos e duas repetições com 30 galinhas por unidade experimental durante 56 dias. Avaliou-se as temperaturas máxima e mínima, bulbo seco, bulbo úmido e de globo negro, umidade relativa, índice de temperatura e umidade e índice de temperatura de globo negro e umidade; a frequência do comportamento natural; produção de ovos por ave/dia, por ave alojada, ovos comercializáveis, viabilidade, consumo de ração, conversão alimentar por dúzia e por massa e qualidade física dos ovos. Os dados foram analisados por meio da análise de variância e as médias comparadas pelo teste $\mathrm{F}$, a 0,05 de probabilidade, exceto a frequência do comportamento que foi analisada pelo teste Quiquadrado. Os índices zootécnicos das aves foram coerentes com as recomendações dos manuais da linhagem. Apenas foi observada diferença significativa para a melhor conversão alimentar por massa das aves criadas sob grama sintética. Desta forma, verifica-se que a grama sintética pode ser um excelente substrato para a cama de galinhas semipesadas na fase de produção.

Palavras-chave: conforto, galinhas poedeiras, grama sintética, maravalha

\section{SUMMARY}

In the system of creation in floor the hens are created directly in contact with the floor that can be covered by different types of materials. The aim of this study was to evaluate the thermal environment, behavior, zootechnical indexes and quality of chicken eggs created in two types of flooring, wooden shavings and synthetic grass, were used 120 semi-heavy laying hens, Hysex Brown $^{\circledR}$, of these, half were created on wooden shaving and half on synthetic grass (Carpet Astro Turf $^{(B)}$ ) distributed in a completely randomized in repeated measures in time in two treatments and two replications of 30 laying hens, during 56 days (two periods of 28 days). Were evaluated temperatures maximum and minimum, dry and wet bulb temperature, black globe temperature, relative humidity, temperature and humidity index and black globe temperature and humidity index; the frequency of natural behavior; the daily egg production per bird, per bird housed, and marketable, viability, feed consumption and feed conversion per dozen and per mass, average egg weight, specific weight and egg shell thickness. Data were analyzed using analysis of variance and means compared by $\mathrm{F}$ test at 0.05 probability, except the frequency of natural behavior that was analyzed using the chi square analysis test. The results show that the values of the zootechnical indexes of the layers are consistent with the guide strains recommendations, having no influence from the kind of floor used as bed. Only significant differences were observed in the feed intakeper mass of birds grown under synthetic grass. Thus, it seems that synthetic grass could be an excellent substrate for the bed of semi-heavy laying hens in the egg production phase.

Keywords: comfort, laying hens, synthetic turf, shavings 


\section{INTRODUÇÃO}

Com o crescimento da indústria avícola surgiram diversas questões relacionadas com o modo como os animais são criados, e os consumidores passaram a se preocupar com a existência de bemestar para as aves e não apenas com a qualidade do produto final.

O bem-estar é um assunto muito discutido entre os consumidores e produtores, sendo hoje um dos requisitos para uma produção considerada de qualidade. A criação em piso é uma boa alternativa para melhorar o bem estar das galinhas poedeiras já que possibilita o enriquecimento do ambiente, como por exemplo, com poleiros e ninhos, e uma maior área por animal. No sistema de criação em piso, as galinhas são criadas diretamente em contato com o chão que pode ser coberto por diferentes tipos de materiais que estimulam o comportamento de espojar no substrato e ciscar. Neste sistema, também existem ninhos que são ambientes calmos e um pouco escuro para as galinhas realizarem a postura.

O modo como as galinhas são criadas tem influência na qualidade e o tempo de prateleira do ovo, sendo que quando a criação é realizada no piso há uma tendência do ovo perder a qualidade, mais rapidamente, devido às excretas $\mathrm{e}$ sujidades no local de oviposição.

Ao avaliar os efeitos de dois sistemas de criação (gaiolas e cama) no desempenho produtivo e na qualidade de ovos de aves poedeiras, Isabrown e Hy-line W-36, Alves et al. (2007) concluiu que quando devidamente projetado, o sistema de criação em cama pode ser compatível ao sistema de criação em gaiolas, pois possibilita a obtenção de mesmo desempenho produtivo e qualidade de ovos produzidos em ambas as linhagens utilizadas. Além disso, quando em condições de menor conforto térmico, pode favorecer a qualidade da casca dos ovos e diminuir as perdas de ovos por trincas.

Desta forma, são necessárias pesquisas para determinar quais os melhores materiais para a cobertura do piso, para que se forneça conforto e favoreça a qualidade dos ovos.

O objetivo deste estudo foi caracterizar o ambiente térmico, avaliar o comportamento, o desempenho zootécnico e a qualidade de ovos provenientes de galinhas poedeiras criadas sobre maravalha e grama sintética.

\section{MATERIAL E MÉTODOS}

O experimento foi realizado no setor de Avicultura do Departamento Acadêmico de Zootecnia do Instituto Federal de Educação, Ciência e Tecnologia do Sudeste de Minas Gerais, Campus Rio Pomba com período préexperimental (adaptação) de 10 dias e o período experimental com duração de 56 dias divididos em dois períodos de 28 dias cada.

Foram utilizadas 120 galinhas poedeiras da linhagem Hisex Brown com 52 semanas de idade, sendo um grupo de 60 aves criadas sobre piso de maravalha e outro grupo de 60 galinhas sobre grama sintética (Tapete Astro $\operatorname{Turf}^{\circledR}$ ), distribuídas em um delineamento inteiramente casualizado em medidas repetidas no tempo, com dois tratamentos e duas repetições com 30 aves por unidade experimental.

As aves foram alojadas em boxe de alvenaria e tela com área de $16 \mathrm{~m}^{2}$. Cada boxe com dois bebedouros pendulares e dois comedouros tubulares, três poleiros e seis ninhos. No centro do boxe foram instalados 
termohigrômetros digitais (Incoterm ${ }^{\circledR}$ ), um termômetro de globo negro e um termohigrômetro analógico de bulbo seco e úmido (Incoterm ${ }^{\mathbb{B}}$ ).

Foram registradas, às 7 e 17 horas, as temperaturas máxima e mínima, temperatura de bulbo seco e bulbo úmido, temperatura de globo negro e umidade relativa do ar sendo utilizados para cálculo do Índice de Temperatura e Umidade (ITU - THOM, 1958) e o Índice de Temperatura de Globo Negro e Umidade (ITGU - BUFFINGTON et al., 1981).

Foi fornecida à vontade aos dois grupos uma ração comercial à base de milho e farelo de soja contendo 164,90g de proteína(Mín), 27g extrato etéreo (Mín), 29,40g de matéria fibrosa (máx), 5000mg de fósforo (Mín), 28,00/45,00 de cálcio (mín/máx), 8.160,00mg de lisina(Mín) e $3.810,00 \mathrm{mg}$ de metionina(mín), sendo esta formulada de forma a atender as exigências nutricionais de aves em fase de postura. A água também foi fornecida à vontade.

Três vezes por semana, às $12 \mathrm{~h}$, foi observada a frequência do comportamento natural durante 15 minutos por boxe com base no seguinte etograma: ciscar no chão; limpar as penas; bater as asas; bicar de investigação; espojar no substrato; empoleirar, comendo e bebendo (PEREIRA et al., 2013).

Foi avaliada a produção de ovos por ave/dia, por ave alojada e ovos comercializáveis; viabilidade das aves; consumo de ração e conversão alimentar por dúzia e por massa e a qualidade dos ovos de cada grupo de aves: peso do ovo, peso específico e espessura da casca.

A produção média de ovos foi obtida computando-se o número de ovos produzidos, incluindo os quebrados, os trincados e os anormais (ovos com casca mole e sem casca) sendo expressa em porcentagem sobre a média de aves do período (ovo/ave/dia) e, sobre o número de aves alojadas no início do experimento (ovo/ave alojada). Para determinação da produção de ovos comercializáveis, em cada período de 28 dias, foi descontado o número de ovos quebrados, trincados, com casca mole e sem casca da produção total de ovos, sendo expressa em porcentagem sobre a média de aves do período (ovos comercializáveis/ave/dia). Para mensuração da postura em ninho ou piso foram computados diariamente o número de ovos de acordo com o local de postura: ninho ou piso.

Todos os ovos íntegros produzidos em cada repetição foram pesados durante os três últimos dias de cada período para assim obter-se o peso médio. $\mathrm{O}$ peso médio dos ovos foi multiplicado pela produção de ovos/ave/dia, calculando-se assim a massa total de ovos.

A conversão alimentar por dúzia de ovos foi calculada pela relação do consumo total de ração em $\mathrm{kg}$ dividido pela dúzia de ovos produzidos $(\mathrm{kg} / \mathrm{dz})$ e a conversão alimentar por massa de ovos calculada pelo consumo de ração em $\mathrm{Kg}$ dividido pela massa total de ovos $(\mathrm{kg} / \mathrm{kg})$.

No $26^{\circ}, 27^{\circ}$ e $28^{\circ}$ dia de cada período foram selecionados com base no peso médio dos ovos de cada parcela, 24 ovos de cada sistema de criação, sendo seis repetições de quatro ovos cada. Os ovos de cada repetição e de cada dia foram pesados individualmente em balança com precisão de $0,001 \mathrm{~g}$.

$\mathrm{O}$ peso específico dos ovos foi determinado no $26^{\circ}, 27^{\circ}$ e $28^{\circ}$ dia de cada período de 28 dias, através da imersão dos ovos íntegros em soluções salinas com densidade variando de 1,060 a $1,095 \mathrm{~g} / \mathrm{cm}^{3}$, com intervalos de 0,005 $\mathrm{g} / \mathrm{cm}^{3}$, devidamente calibradas por meio de um densímetro (OM-5565, Incoterm $\left.{ }^{\circledR}\right) \quad$ conforme descrito por Oliveira; Oliveira (2013). Após a 
quebra dos ovos (região equatorial), as cascas foram lavadas e secas em estufa de circulação de ar forçada por 48 horas a $65^{\circ} \mathrm{C}$, em seguida foram feitas medidas de fragmentos da casca nos dois polos e no meio do ovo. A espessura da casca de cada repetição foi determinada pela média aritmética das três medidas.

Os parâmetros foram analisados por meio da análise de variância e as médias comparadas pelo teste $\mathrm{F}$ a 0,05 de probabilidade pelo programa estatístico SISVAR (FERREIRA, 2014). A frequência do comportamento natural foi analisada por meio do teste Quiquadrado $\left(\chi^{2}\right)$.

\section{RESULTADOS E DISCUSSÃO}

O tipo de material utilizado como cama e a interação entre o tipo de material e período experimental não foram significativos $\quad(p>0,05)$ para as características do ambiente no interior das instalações (Tabela 1). Ao analisar o período, apenas para a temperatura máxima não houve alteração significativa $(p>0,05)$. Os dados do primeiro período foram obtidos no final do inverno, enquanto os dados do segundo período foram mensurados no início da primavera, o que justifica as diferenças encontradas para as demais variáveis.

Baêta; Souza (2010) descreveram, para aves, ITGU até 74 é seguro e entre 74 e 78 exigem certos cuidados, assim, no segundo período o ITGU estava acima do valor considerado seguro $(75,58)$.

A alta temperatura e o maior ITGU mensurado no segundo período experimental promoveu alteração $(\mathrm{p}>0,05)$ nos índices zootécnicos, exceto aumento $(\mathrm{p}<0,05)$ na taxa de ovos trincados (Tabela 2) e piora $(\mathrm{p}<0,05)$ na espessura da casca dos ovos (Tabela 3).

Sabe-se que, sob estresse por calor, como no segundo período experimental, a ave pode apresentar impactos negativos sobre o desempenho produtivo e a qualidade dos ovos. Segundo Albino et al. (2014) com o aumento da temperatura ambiente, a ave para manter a temperatura corporal tende a aumentar sua frequência respiratória, interferindo em muitos processos naturais como a eliminação de $\mathrm{CO}_{2}$, que acarretará na diminuição e disponibilidade de bicarbonatos $\left(\mathrm{HCO}_{3}\right)$ utilizados na formação da casca do ovo, comprometendo-a.

Ao avaliar os efeitos do ambiente bioclimático sobre a qualidade de ovos de aves poedeiras, Alves et al. (2007) observou na análise da espessura da casca, nos períodos de maior estresse por calor, que os ovos apresentaram casca mais fina, principalmente aqueles provenientes das aves em gaiolas, o que ocasionou diferenças significativas entre sistemas de criação (gaiola e cama).

Não houve diferença significativa $(p>0,05)$ para ovos postos em ninhos e no piso, entretanto é visível a diferença numérica desses parâmetros. $\mathrm{O}$ fato do coeficiente de variação ter sido alto pode ter contribuído para que não pudesse detectar diferença estatística, o que sugere que para mensurar esses parâmetros seja necessário um maior número de repetições. Foi possível observar maior dificuldade de coletar os ovos postos sobre a maravalha, uma vez que as galinhas enterravam os ovos, além da postura ocorrer em locais de difícil acesso como debaixo dos ninhos, o que consequentemente aumentou o número de ovos sujos e a taxa de ovos trincados (Tabela 2). 
Tabela 1. Índices ambientais da instalação do galpão de alojamento de galinhas poedeiras Hisex Brown criadas sob diferentes tipos de materiais usados como cama

\begin{tabular}{|c|c|c|c|c|c|c|c|c|}
\hline \multirow{2}{*}{ Parâmetros } & \multicolumn{2}{|c|}{$\begin{array}{l}\text { Tipo de material usado como } \\
\text { cama }\end{array}$} & \multicolumn{2}{|c|}{ Período } & \multicolumn{3}{|c|}{ Valores de P } & \multirow{2}{*}{$\begin{array}{l}\mathrm{CV} \\
(\%)\end{array}$} \\
\hline & Maravalha & Grama Sintética & 1 & 2 & $\begin{array}{l}\text { Tipo de } \\
\text { material }\end{array}$ & Período & $\begin{array}{c}\text { Tipo de material } \\
\text { X Período }\end{array}$ & \\
\hline Temperatura máxima $\left({ }^{\circ} \mathrm{C}\right)$ & 30,68 & 30,98 & 29,05 & 32,60 & 0,3743 & 0,0723 & 0,9977 & 0,92 \\
\hline Temperatura mínima $\left({ }^{\circ} \mathrm{C}\right)$ & 19,42 & 19,35 & 18,10 & $20,68^{*}$ & 0,6560 & 0,0195 & 0,6580 & 0,91 \\
\hline Umidade relativa (\%) & 73,00 & 74,25 & 85,98 & $61,28^{*}$ & 0,1500 & 0,0254 & 0,8410 & 0,58 \\
\hline Temperatura de bulbo seco $\left({ }^{\circ} \mathrm{C}\right)$ & 24,40 & 24,23 & 20,75 & $27,88^{*}$ & 0,2578 & 0,0102 & 0,7523 & 0,44 \\
\hline Temperatura de bulbo úmido $\left({ }^{\circ} \mathrm{C}\right)$ & 20,65 & 20,68 & 19,18 & $22,15^{*}$ & 0,7958 & 0,0029 & 0,6352 & 0,51 \\
\hline Temperatura de globo negro $\left({ }^{\circ} \mathrm{C}\right)$ & 24,15 & 23,98 & 20,60 & $27,53^{*}$ & 0,2578 & 0,0111 & 0,7527 & 0,44 \\
\hline $\begin{array}{l}\text { ITU (Índice de Temperatura e } \\
\text { Umidade) }\end{array}$ & 72,68 & 72,53 & 68,42 & $76,78^{*}$ & 0,3743 & 0,0032 & 0,6048 & 0,19 \\
\hline $\begin{array}{l}\text { ITGU (Índice de Temperatura de } \\
\text { Globo Negro e Umidade) }\end{array}$ & 72,20 & 72,00 & 68,62 & $75,58^{*}$ & 0,2753 & 0,0111 & 0,7543 & 0,18 \\
\hline
\end{tabular}

*Médias distintas pelo teste $\mathrm{F}(\mathrm{p}<0,05)$

$\mathrm{CV}=$ Coeficiente de Variação. 
Tabela 2. Desempenho zootécnico de galinhas poedeiras Hisex Brown criadas sob diferentes tipos de materiais utilizados como cama

\begin{tabular}{|c|c|c|c|c|c|c|c|c|}
\hline \multirow[b]{2}{*}{ Parâmetros } & \multicolumn{2}{|c|}{$\begin{array}{l}\text { Tipo de material usado } \\
\text { como cama }\end{array}$} & \multicolumn{2}{|c|}{ Período } & \multicolumn{3}{|c|}{ Valores de P } & \multirow[b]{2}{*}{$\mathrm{CV}(\%)$} \\
\hline & Maravalha & $\begin{array}{l}\text { Grama } \\
\text { Sintética }\end{array}$ & 1 & 2 & $\begin{array}{l}\text { Tipo de } \\
\text { material }\end{array}$ & Período & $\begin{array}{c}\text { Tipo de } \\
\text { material } \\
\text { X Período }\end{array}$ & \\
\hline Postura de ovos no ninho (\%) & 73,49 & 92,41 & 83,02 & 82,88 & 0,2711 & 0,9745 & 0,8367 & 14,63 \\
\hline Postura de ovos no piso (\%) & 21,82 & 4,34 & 13,56 & 12,61 & 0,3293 & 0,8895 & 0,9628 & 107,51 \\
\hline Produção de ovos /ave/ dia (\%) & 95,32 & 96,75 & 96,58 & 95,48 & 0,4844 & 0,6751 & 0,8085 & 2,01 \\
\hline Produção de ovos/ ave alojada (\%) & 93,69 & 93,87 & 94,88 & 92,68 & 0,9498 & 0,4686 & 0,7594 & 3,41 \\
\hline $\begin{array}{l}\text { Produção de ovos comercializáveis } \\
(\% / \text { ave/dia })\end{array}$ & 93,82 & 95,70 & 95,64 & 93,88 & 0,2384 & 0,5051 & 0,7565 & 1,10 \\
\hline Taxa de ovos trincados $(\%)$ & 1,56 & 1,09 & 0,98 & $1,68 *$ & 0,5915 & 0,0066 & 0,1792 & 67,27 \\
\hline Viabilidade $(\%)$ & 98,30 & 97,50 & 97,50 & 98,30 & 0,8039 & 0,7272 & 0,7091 & 3,65 \\
\hline Massa de ovos (g/ave/dia) & 59,44 & 60,35 & 60,23 & 59,56 & 0,3514 & 0,7279 & 0,8265 & 1,32 \\
\hline Consumo de ração (g/ave/dia) & 123,25 & 118,00 & 123,75 & 117,50 & 0,1488 & 0,0638 & 0,2319 & 1,47 \\
\hline Conversão alimentar (kg/dúzia) & 1,55 & 1,46 & 1,54 & 1,48 & 0,0924 & 0,1550 & 0,4042 & 1,17 \\
\hline Conversão alimentar (kg/kg) & 2,07 & $1,96^{*}$ & 2,05 & 1,97 & 0,0389 & 0,1741 & 0,4428 & 0,49 \\
\hline
\end{tabular}

*Médias distintas pelo teste $\mathrm{F}(\mathrm{p}<0,05)$.

$\mathrm{CV}=$ Coeficiente de Variação 
A produção de ovos por ave/dia, produção de ovos por ave alojada e produção de ovos comercializáveis não apresentaram alterações significativas $(\mathrm{p}>0,05)$, sendo que os valores mostrados na Tabela 2 estão acima do esperado para a linhagem $(>80 \%$ entre 50 e 60 semanas de idade), o que demonstra que independente do piso a produção foi satisfatória.

Em relação à taxa de ovos trincados houve diferença significativa $(p<0,05)$ para o período. Foi observado aumento na taxa de ovos trincados com o avançar do tempo, e isso se deve a idade das poedeiras e ao aumento da temperatura, pois, à medida que aumenta a idade da ave, a qualidade de casca diminui consideravelmente, uma vez que há aumento no tamanho do ovo e menor mobilização e absorção de cálcio pela ave (PIRES et al., 2015). Este resultado corrobora com Alves et al. (2007), que ao avaliar os efeitos de dois sistemas de criação (gaiolas e cama) no desempenho produtivo e na qualidade de ovos de aves poedeiras concluiu que a menor espessura observada das cascas dos ovos das aves em gaiolas nos períodos de maior estresse por calor pode ter tornado os ovos mais suscetíveis às trincas.

Não houve diferença $(p>0,05)$ para viabilidade. Segundo o Manual da de Manejo da Linhagem Hisex Brown (2006), é ideal uma viabilidade superior a $93 \%$ no período de produção (18-80 semanas). Constatou-se que tanto para o tipo de piso quanto para o período experimental, a viabilidade foi acima do esperado para a linhagem.

Não se observou alteração $(p>0,05)$ para massa de ovos (g/ave/dia), sendo que os valores observados durante $\mathrm{o}$ experimento estão acima do esperado para a linhagem que é de 53,0 a 54,4 g/ave/dia entre 50 e 60 semanas de idade. Resultados semelhantes foram encontrados por Camerini et al. (2013) que ao estudar os efeitos de dois sistemas de criação (gaiola enriquecida e sistema alternativo) e a influência de três condições ambientais $\left(20^{\circ} \mathrm{C}, 26^{\circ} \mathrm{C}\right.$ e $32^{\circ} \mathrm{C}$ ), não encontrou diferença significativa para massa de ovos.

Observou-se valores médios de massa de ovos de 59,44 g/ave/dia produzidos sob maravalha e de 60,35 g/ave/dia produzidos por galinhas alojadas sob grama sintética, o que indica, segundo o Decreto Lei $\mathrm{N}^{\circ} 56.585$, de 20 de julho de 1965, Art. $6^{\circ}$, que os ovos produzidos sob maravalha seriam classificados como tipo 2 (grande) com peso mínimo de 55 (cinquenta e cinco) gramas por unidade - e os ovos produzidos sob a grama sintética como tipo 1 (extra) - com peso mínimo de 60 (sessenta) gramas por unidade.

Para o consumo de ração (g/ave/dia) e a conversão alimentar por dúzia, não houve diferença significativa $(\mathrm{p}>0,05)$. De acordo com o Manual de Manejo da Linhagem Hisex Brown, o consumo de ração esperado é de 110 a $112 \mathrm{~g} / \mathrm{ave} / \mathrm{dia}$. Notou-se que o consumo foi maior, o que sugere desperdício de ração, especialmente das aves mantidas em piso de maravalha.

A conversão alimentar por dúzia ideal é de $1,4, \mathrm{~kg}$ /dúzia, valor próximo do observado na pesquisa. Já para a conversão alimentar por massa houve diferença significativa $(\mathrm{p}<0,05)$ para o tipo de piso utilizado como cama, sendo que as galinhas criadas sob grama sintética apresentaram melhor valor $(1,96 \mathrm{~kg} / \mathrm{kg})$, bem abaixo do indicado pelo Manual da Linhagem que é de 2,17 $\mathrm{kg} / \mathrm{kg}$. Isso sugere que houve menor desperdício de ração pelas aves criadas sob grama sintética, algo importante em relação ao aspecto econômico, visto que a ração representa $70 \%$ do custo total de produção. 
Não se observou diferenças significativas para os parâmetros de qualidade de ovos, peso do ovo e peso específico, exceto para a espessura da casca em função do período avaliado (Tabela 3).

A espessura da casca piorou $(\mathrm{p}<0,05)$ no segundo período de avaliação. Segundo Ahmadi \& Rahimi (2011), o tamanho do ovo aumenta com o avançar da idade da galinha, ao mesmo tempo, o peso da casca aumenta ou permanece o mesmo. De qualquer forma, o maior peso do ovo não é acompanhado por um aumento proporcional da espessura da casca de modo que os ovos são de maior tamanho e apresentam menor proporção da casca.

Tabela 3. Médias do peso do ovo, peso específico e espessura da casca de poedeiras Hisex Brown criadas sob diferentes tipos de materiais usados como cama

\begin{tabular}{|c|c|c|c|c|c|c|c|c|}
\hline \multirow[b]{2}{*}{ Parâmetros } & \multicolumn{2}{|c|}{$\begin{array}{c}\text { Tipo de material } \\
\text { usado como cama }\end{array}$} & \multicolumn{2}{|c|}{ Período } & \multicolumn{3}{|c|}{ Valores de F } & \multirow[b]{2}{*}{$\begin{array}{l}\mathrm{CV} \\
(\%)\end{array}$} \\
\hline & Maravalha & $\begin{array}{l}\text { Grama } \\
\text { Sintética }\end{array}$ & 1 & 2 & $\begin{array}{l}\text { Tipo de } \\
\text { material }\end{array}$ & Período & $\begin{array}{c}\text { Tipo de } \\
\text { material X } \\
\text { Período }\end{array}$ & \\
\hline Peso do ovo (g) & 62,36 & 62,37 & 62,36 & 62,37 & 0,9883 & 0,9830 & 0,9500 & 0,68 \\
\hline $\begin{array}{l}\text { Peso específico } \\
\left(\mathrm{g} / \mathrm{cm}^{3}\right)\end{array}$ & 1,093 & 1,094 & 1,094 & 1,094 & 0,500 & 0,3910 & 0,0577 & 0,10 \\
\hline $\begin{array}{l}\text { Espessura da } \\
\text { casca }(\mathrm{mm})\end{array}$ & 0,5293 & 0,5153 & 0,5515 & $0,4930 *$ & 0,1344 & 0,0112 & 0,2721 & 0,81 \\
\hline
\end{tabular}

*Médias distintas pelo teste $\mathrm{F}(\mathrm{p}<0,05)$.

$\mathrm{CV}=$ Coeficiente de Variação.

O peso específico do ovo pode variar de 1,050 a $1,100 \mathrm{~g} / \mathrm{cm}^{3}$, sendo que quanto maior a gravidade específica melhor é a qualidade do ovo. Logo, os ovos avaliados no presente estudo apresentaram ótima qualidade, independentemente do tipo de piso ou do período de avaliação.

Ambos os pisos, maravalha e grama sintética, proporcionaram as galinhas poedeiras a expressão do comportamento natural, já que não houve alteração significativa $(p>0,05)$ pelo teste de qui-quadrado (Tabela 4).

Notou-se que, apesar de não siginifcativo, as galinhas mantidas sob a maravalha apresentaram maior frequência de ocorrência dos seguintes comportamentos ciscando, limpando as penas, batendo as asas, espojando no substrato e empoleirando comparadas com as galinhas criadas sobre grama sintética. Em contrapartida, as galinhas criadas sobre grama sintética tiveram maior frequência de ocorrência dos comportamentos comendo e bebendo, porém, apesar do maior tempo gasto comendo, a conversão alimentar por massa foi melhor. O que está de acordo com o observado por Pereira et al. (2013) que ao determinar diferenças comportamentais entre poedeiras criadas sob diferentes densidades $\mathrm{e}$ tamanhos de grupo, em condições de ambiente enriquecido, verificou a ocorrência da maior frequência dos comportamentos de comer e beber. 
Tabela 4. Valores percentuais de tempo médio em que poedeiras Hisex Brown criadas sob diferentes tipos de materiais usados como cama, expressaram seus comportamentos

\begin{tabular}{|c|c|c|}
\hline \multirow{2}{*}{ Comportamento } & \multicolumn{2}{|c|}{ Tipo de material usado como cama } \\
\hline & Maravalha & Grama Sintética \\
\hline Ciscar & 11,5 & 4,2 \\
\hline Limpar as penas & 14,8 & 11,7 \\
\hline Bater as asas & 1,7 & 0,6 \\
\hline Bicar de investigação & 12,9 & 12,9 \\
\hline Espojar no substrato & 3,9 & 2,0 \\
\hline Empoleirar & 4,3 & 3,9 \\
\hline Comendo & 27,1 & 30,3 \\
\hline Bebendo & 23,8 & 34,5 \\
\hline Total & 100 & 100 \\
\hline Valor do Qui-quadrado & \multirow{2}{*}{\multicolumn{2}{|c|}{$\begin{array}{c}7,670 \\
14,067^{\text {ns }}\end{array}$}} \\
\hline P-Valor & & \\
\hline
\end{tabular}

Desta forma, verifica-se que a grama sintética pode ser um excelente substrato para a cama, uma vez que proporciona adequado conforto térmico, excelentes resultados de desempenho zootécnico e de qualidade de ovos, além de proporcionar que as galinhas exerçam seu comportamento natural.

Os diferentes tipos de materiais utilizados como cama, maravalha e grama sintética, proporcionaram bom estado de conforto térmico, a expressão do comportamento natural, excelente qualidade dos ovos e desempenho zootécnico, contudo, há que se considerar que as galinhas mantidas sobre grama sintética apresentaram melhor conversão alimentar $(\mathrm{kg} / \mathrm{kg})$.

\section{REFERÊNCIAS}

AHMADI, F.; RAHIMI, F. Factors affecting quality and quantity of egg production in laying hens: a review. World Applied Sciences Journal, v.12, n.3, p.372-384, 2011.
ALBINO, L.F.T.; CARVALHO, B.R. de; MAIA, R.C.; BARROS, V.R.S.M. de Galinhas Poedeiras: criação e alimentação. 1.ed. - Viçosa: Aprenda Fácil, 2014. 376p.

ALVES, S.P.; SILVA, I.J.O.; PIEDADE, S.M.S.. Avaliação do bemestar de aves poedeiras comerciais: efeitos do sistema de criação e do ambiente bioclimático sobre $o$ desempenho das aves e a qualidade de ovos. Revista Brasileira de Zootecnia, v.36, n.5, p.1388-1394, 2007.

BAÊTA, F.C.; SOUZA, C.F.. Ambiência em edificações rurais: conforto térmico. 2. ed. Viçosa, MG: Universidade Federal de Viçosa, 2010. 269p.

BRASIL. Decreto Lei n 56.585, de 20 de julho de 1965. Classificação e fiscalização do ovo. Disponível em: $<$ http://www2.camara.leg.br/legin/fed/d ecret/1960-1969/decreto-56585-20julho-1965-396950-publicacaooriginal1-pe.html> Acesso em 08 dez. 2015. 
BUFFINGTON, D.E.;COLLAZO-

AROCHO, A.; CANTON, G.H.; PITT, D.; THATCHER, W.W.; COLLIER, R.J.. Black globe-humidity index (BGHI) as comfort equation for dairy cows. Transation of the ASAE, v.24, n.3, p.711-714, 1981.

CAMERINI, N.L.; OLIVEIRA, D.L.; SILVA, R.C.; NASCIMENTO, J.W.B.; FURTADO, D.A.. Efeito do sistema de criação e do ambiente sobre a qualidade de ovos de poedeiras comerciais.

Engenharia na Agricultura, v.21, n.4, p.334-339, 2013.

FERREIRA, D.F. Sisvar: a Guide for its Bootstrap procedures in multiple comparisons. Ciência e

Agrotecnologia, v.38, n.2, p.109-112, 2014.

Manual de manejo Hisex Brown.

Interaves - Avicultura com Tecnologia. 2006. Disponível em:

$<$ http://avicultura.globoaves.com.br>. Acesso em: 14 jan. 2016.

OLIVEIRA, B.L.; OLIVEIRA, D.D.

Qualidade e tecnologia de ovos.

Lavras: UFLA, 2013. 223 p.

PEREIRA, D.F.; BATISTA, E.S.;

SANCHES, F.T.; FILHO, L.R.A.G.;

BUENO, L.G.F.Comportamento de poedeiras criadas a diferentes densidades e tamanhos de grupo em ambiente enriquecido. Pesquisa Agropecuária Brasileira [online], v.48, n.6, p.682-688, 2013.

PIRES, M.F.; PIRES, S.F.; ANDRADE, C.L.; CARVALHO, D.P.; BARBOSA, A.F.C.; MARQUES, M.R. Fatores que afetam a qualidade dos ovos de poedeiras comerciais. Revista

Eletrônica Nutritime, v.12, n.6, 2015. Disponível em:

$<$ http://www.nutritime.com.br/arquivos _internos/artigos/339_-_4379-4385_-
NRE 12-6 nov-dez 2015.pdf $>$

Acesso em: 07 de dez. de 2015.

THOM, E.C. Cooling degrees - days air conditioning, heating, and ventilating. Transactions of the ASAE, v. 55, n.7, p.65-72, 1958.

Data de recebimento: 16/02/2017

Data de aprovação: 10/05/2017 